\title{
Complete haematological response to Imatinib in chronic myeloid leukaemia patients attending the Ocean Road Cancer Institute in Tanzania
}

\author{
ERIUS TEBUKA ${ }^{1,2}$, ABEL MAKUBI ${ }^{2 *}$ and KHAMZA MAUNDA ${ }^{3}$ \\ ${ }^{1}$ Catholic University of Health and Allied Sciences, Mwanza Tanzania \\ ${ }^{2}$ Muhimbili University of Health and Allied Sciences, School of Medicine, P.O Box 65001, Dar es Salaam, Tanzania \\ 3 Department of Oncology, Ocean Road Cancer institute Dar es Salaam, Tanzania
}

\begin{abstract}
Background: There is limited information on clinical characteristics, diagnosis and response to therapy of patients with chronic myeloid leukaemia (CML) in Tanzania. This hospital-based retrospective and crosssectional study was conducted to describe the clinical and laboratory characteristics, time to diagnosis and response to first line therapy with imatinib in Philadelphia chromosome positive CML.

Methods: The study was conducted at the Ocean Road Cancer Institute in Dar es Salaam, Tanzania. Participants were sequentially recruited from the outpatient clinic where a structured questionnaire was employed seeking details socio-clinical features of the disease. Haematology indices at baseline and at three months of treatment was obtained from patient's medical records. Haematological response was determined at three months of imatinib use using leukaemia net definition.

Results: Of 127 study participants, 63\% were males. The mean ( \pm standard deviation) age at diagnosis was $40( \pm 16)$ years, majority being in the third decade of life. Abdominal distention (88\%) and symptoms of anaemia (84\%) were the most frequent complaints. Splenomegaly (92\%) and pallor (82.7\%) were the common physical findings. The mean duration from consultation to diagnosis was $3( \pm 0)$ weeks and mean duration from diagnosis to imatinib therapy initiation was $3( \pm 0.9)$ weeks. A total of $116(91.3 \%)$ of patients had complete haematological response to imatinib therapy three months after therapy. There was significant decline in total white blood cell counts, basophils count, platelets and increase in haemoglobin at three months after imatinib therapy initiation.

Conclusion: Majority of patients were young with clinical and laboratory findings of severe disease. Patients presented late to hospital and there was a considerable long time to reach a final diagnosis and yet haematological response was still achieved in majority of these patients with imatinib therapy. The elucidated clinical and laboratory findings should advocate early CML diagnosis and immediate referral to a tertiary hospital.
\end{abstract}

Keywords: Clinical, laboratory, characteristics, time to diagnosis, chronic leukaemia, Tanzania

\section{Introduction}

Chronic myelogenous leukaemia (CML) is a myeloproliferative disorder of pluripotent hematopoietic stem cells (Fialkow et al., 1997). Cancer statistics in the United States estimate 5,980 new case and 810 deaths due CML for 2013 alone (Siegel et al., 2013). Local anecdotal evidence show that CML is among the leading diagnosis in patients with haematological malignancies in Tanzania. The Philadelphia chromosome (Ph), the hallmark cytogenetic abnormality of CML, is identified in the bone marrow cells of more than $90 \%$ of patients with the clinical and laboratory features of CML (Rowley, 1973)

CML has a triphasic or biphasic clinical course. This is a chronic phase, which is present at the time of diagnosis in approximately $85 \%$ of patients. It is an accelerated phase, in which neutrophil differentiation becomes progressively impaired and leukocyte counts are more difficult to control with treatment and blast crisis, a condition resembling acute leukaemia in which myeloid or lymphoid blasts proliferate in an uncontrolled manner (Stefan Faderl, 1999). The clinical findings at diagnosis of CML vary among reported series and also depend upon the stage of disease at diagnosis. Twenty to fifty percent of patients are asymptomatic, with the disease first being suspected from routine blood tests (Savage et al., 1997; Stefan Faderl, 1999). Among symptomatic

\footnotetext{
*Correspondence E-mail: makubi55@gmail.com
} 
patients, systemic symptoms such as fatigue, malaise, weight loss, excessive sweating, abdominal fullness and bleeding episodes due to platelet dysfunction are common (Savage et al., 1997). A few studies in Africa have reported clinical presentation of $C M L$ to include features attributed to splenic enlargement in majority of the patients (Mukiibi et al., 2003; Sissolak et al., 2015) with anaemia accounting for two thirds of the patients followed by hepatomegaly and lymphadenopathy in a quarter of patients. Splenomegaly of $<10 \mathrm{~cm}$ is known to be associated with better progression free survival than those of splenomegaly of $>10 \mathrm{~cm}$ (Oyekunle et al., 2015). Thus more studies might improve awareness of clinical presentations of the disease in our locality and strengthen referral systems.

There also is paucity of data regarding magnitude delays in cancer diagnosis in Tanzania and Africa as a whole (Busolo \& Woodgate, 2015). Delays in presentation with symptoms among patients with leukaemia and other cancers is likely to contribute to late stage at diagnosis and, thereby, poor survival rate (Neal, 2009). A few studies have defined patient delays and primary care delays as the total time from symptoms onset to a specialist consultation (Weller et al., 2012; Howell et al., 2015). It has been reported that CML patients may wait for more than three months before consulting a physician and risk of waiting more than three months was increased among those with unusual sweating, pain/discomfort in the abdomen, pallor, extreme weakness and fatigue indicating a lack of public awareness (Howell et al.. 2013). However, information on time intervals from symptoms onset to final diagnosis and time to treatment is poorly known in most of the African countries. This needs to be studied because delays in presentation among patients with leukaemia and other cancers is likely to contribute to late stage at diagnosis and hence poor outcome (Neal, 2009). Early diagnosis and referral of CML patients like many other haematological malignancies have resulted in better overall survival rate (Howell et al., 2015)

Many studies have reported achievement of complete haematological response for more than $90 \%$ of patients to imatinib within three months of therapy (Gupta \& Prasad, 2007; Nair et al., 2014). Complete hematologic response (CHR) is defined by a white blood cell count $<10,000 / \mathrm{microL}$ with no immature granulocytes and $<5$ percent basophils on differential; platelet count $<450,000 / \mu \mathrm{L}$; and spleen not palpable (Baccarani et al., 2009). Imatinib (Glivec), a very selective tyrosine kinase inhibitor used in CML patients is highly efficient by achieving complete haematological response to the drug within three months of therapy and is associated with good overall survival and progression free survival (Hanfstein et al., 2015; Soverini et al., 2016). Failure to attain a complete hematologic response by three months is an indication for a change in therapy. (Hanfstein et al., 2015). Patients with resistance/lack response will benefit from early change to second generation tyrosine kinase inhibitor. This study was conducted to describe the clinical and laboratory characteristics, time to diagnosis and response to first line therapy with imatinib among patients attending care at the Ocean Road Cancer Institute (ORCI) in Dar es Salaam, Tanzania.

\section{Materials and Methods}

\section{Study design and population}

This was both a retrospective and cross sectional study that conducted at $\mathrm{ORCl}$ which is a 350 bed hospital specialised for care of cancer patients and receives patients referred from all regions of Tanzania. A special clinic is conducted and Imatinib is provided to Philadelphia positive CML patients under a special programme known as Glivec Patient Assistance Programme. The study included all patients diagnosed with Philadelphia positive CML attending clinic at the Institute from September 2015 - January 2016. Patients who were on imatinib less than 3 months were excluded from the study.

\section{Data collection}

Consenting patients were retrospectively asked about time from haematology consultation to final diagnosis; and time from final diagnosis to imatinib initiation. Clinical files were used to gather 
information on socio-demographic characteristics, chief complaints, symptoms duration, blood transfusion history prior to treatment, complete blood count indices, spleen size, dosage of imatinib and other relevant physical findings, duration of imatinib use and bone marrow blast count. While patients were seen at different times of exposure to the treatment, complete blood counts $(C B C)$ and differential, presence or absence of spleen at three months after commencement of imatinib therapy was obtained from medical records to define complete haematological response. Ph chromosome positive CML patients undergo initial liver and renal biochemical tests before commencement of imatinib at 40omg orally, once every day. Patients are followed monthly for the first three months with biochemical tests and complete blood counts and a thorough physical examination. At the end of three months, patients are assessed for attainment of haematological response by physical examination, complete blood count with differential as defined by leukemiaNet CML guidelines (Baccarani et al., 2009).

Duration of symptoms was defined as time from onset of symptoms related to CML to first haematology specialist consultation. While time to diagnosis was defined as time from first haematology consultation to bone marrow diagnosis or FISH for BCR-ABL gene consistent with $C M L$, while time to treatment initiation was defined as time from final $C M L$ diagnosis to imatinib initiation.

\section{Laboratory tests}

Full blood pictures were done using a haematology analyser (Beckman Coulter ACT5 DIFF). Bone marrow diagnosis of CML was made by microscopic cytology examination of bone marrow aspirate obtained from right/left posterior iliac crest under aseptic technique, smeared onto 3-4 glass slides, fixed in $70 \%$ methanol and stained with Leishman. Molecular diagnosis was done by using real time polymerase chain reaction for detection of $B C R-A B L$ fusion gene by GeneXpert system that automatically amplifies the nucleic acid and with the use of special probes detects the $B C R-A B L$ fusion gene.

\section{Data analysis}

The collected data was checked for quality and coding was done prior to entering into the computer using SPSS (Version 20.0) statistical programme, which was used for analysis. Continuous data were summarized using means. Differences of parameters across sex were compared using Chi-square test. Comparisons of means between hematological parameters before and after treatment was calculated using student $t$ test and Fischer's exact test. The differences were considered to be significant if $p$-values were less than 0.05 .

\section{Ethical considerations}

Ethical clearance was sought from the Research and Publications Committee of Muhimbili University of Health and Allied Sciences. The permission to conduct this study was sought from authorities of $\mathrm{ORCl}$. A formal written informed consent, in Kiswahili, was sought from the participants. Non consenting patients had equal access to consultation and medical services.

\section{Results}

\section{Characteristics of study participants}

Of the total 127 study participants, 80 (63\%) were males. Mean (SD) age at interview was $43 \pm 16$ years, majority being in the fourth decade; youngest being 11 years and oldest 84 years (Table 1 ). Abdominal distension and fatigue were the most frequent complaints across study participants 112 (88.2\%) and 107 (84.3\%), respectively. Other signs are summarised in Table 1. 
Table1: Socio-demographic and clinical characteristics of Philadelphia positive CML by sex

\begin{tabular}{|c|c|c|c|c|}
\hline Variable & All n (\%) & Male n (\%) & Female $\mathbf{n}(\%)$ & P-value \\
\hline Mean age at diagnosis(SD)* & $40(16.2)$ & $39(15.1)$ & $40(18.0)$ & 0.694 \\
\hline Mean age at interview(SD)* & $43(16)$ & $42(15 \cdot 3)$ & $44(17 \cdot 3)$ & 0.628 \\
\hline \multicolumn{5}{|l|}{ Marital status } \\
\hline Married & $88(69)$ & $57(65)$ & $3(35.2)$ & $<0.001$ \\
\hline Unmarried & $39(31)$ & $23(59)$ & $16(41)$ & \\
\hline Level of education & & & & 0.602 \\
\hline No formal education & $11(8.7)$ & $8(73)$ & $3(28)$ & \\
\hline Primary school & $59(46.5)$ & $33(56)$ & $26(44)$ & \\
\hline Secondary school & $33(26.0)$ & $23(70)$ & $10(30)$ & \\
\hline University & $22(17 \cdot 3)$ & $15(68)$ & $7(32)$ & \\
\hline Others & $2(1.6)$ & $1(50)$ & $1(50)$ & \\
\hline Employment & & & & 0.024 \\
\hline Civil servant & $24(18.9)$ & $13(54)$ & $11(46)$ & \\
\hline Private sector & $19(15)$ & $18(95)$ & $1(5)$ & \\
\hline Farmer/peasant & $30(23.6)$ & $15(50)$ & $15(50)$ & \\
\hline Self employed & $37(29.1)$ & $23(62)$ & $14(38)$ & \\
\hline Others & $17(13.4)$ & $11(65)$ & $6(35)$ & \\
\hline \multicolumn{5}{|l|}{ Comorbidities } \\
\hline Hypertension & $11(8.7)$ & $8(73)$ & $3(27)$ & 0.96 \\
\hline Diabetes & $3(2.4)$ & $1(50)$ & $2(50)$ & $0.55^{*}$ \\
\hline Others comorbidities* & $2(1.6)$ & $1(50)$ & $1(50)$ & $1 *$ \\
\hline \multicolumn{5}{|l|}{ Symptoms } \\
\hline Fatigue & $112(88.2)$ & $69(62)$ & $43(38)$ & 0.377 \\
\hline Abdominal distension & $107(84 \cdot 3)$ & $68(64)$ & $39(36)$ & 0.763 \\
\hline Body malaise & $63(49.6)$ & $39(62)$ & $24(38)$ & 0.801 \\
\hline Awareness of heartbeats & $58(45.7)$ & $34(57)$ & $24(43)$ & 0.350 \\
\hline Weight loss & $51(40.2)$ & $30(59)$ & $21(41)$ & 0.425 \\
\hline Excessive sweating & $32(25.2)$ & $19(59)$ & $13(41)$ & 0.624 \\
\hline Previous blood transfusion & $17(13.4)$ & $8(47)$ & $9(53)$ & 0.144 \\
\hline Bleeding & $1(0.8)$ & $1(100)$ & $0(0)$ & 0.630 \\
\hline Priapism & $4(3.1)$ & $4(100)$ & $4(100)$ & NA \\
\hline Others symptoms* & $12(9.4)$ & 8 & 2 & $0.18 *$ \\
\hline \multicolumn{5}{|l|}{ Signs } \\
\hline Pallor & $105(82.7)$ & $68(68)$ & $37(32)$ & 0.025 \\
\hline Splenomegaly & $118(92.9)$ & $75(65)$ & $43(35)$ & 0.153 \\
\hline No palpable spleen & $9(7)$ & $5(55.6)$ & $4(44.4)$ & \\
\hline Massive Splenomegaly & $73(61.8)$ & $48(65.8$ & $25(34.2)$ & \\
\hline Non massive splenomegaly & $24(20.3)$ & $15(62.5)$ & $9(37.5)$ & \\
\hline Undocumented spleen size & $21(17.8)$ & $11(52.4)$ & $10(47.6)$ & \\
\hline Jaundice & $12(0.4)$ & $4(33)$ & $8(67)$ & 0.632 \\
\hline Hepatomegaly & $29(22.8)$ & $15(52)$ & $14(48)$ & 0.632 \\
\hline Lymphadenopathy & $9(7.1)$ & $5(55.5)$ & $4(44 \cdot 5)$ & $0.725^{*}$ \\
\hline Lower limb oedema & $7(5.5)$ & $6(85)$ & $1(15)$ & $0.258 *$ \\
\hline Skin nodules & $9(7.1)$ & $6(68)$ & $3(32)$ & $1.00 *$ \\
\hline Others signs* & $4(3.2)$ & $3(75)$ & $1(25)$ & $0.482 *$ \\
\hline
\end{tabular}

Test static was Pearson chi square, unless otherwise stated *Fischer's exact test. NA = Not applicable. Other symptoms*: hearing loss (3), vision loss (1), lower limb swelling (2), skin swellings/nodules (1), fever (1), Bleeding 1, muscle \& leg pain (1), vision \& hearing loss (1), bone pain (1). Other signs*: Fever (1), bone tenderness (1), Conjunctiva haemorrhage

\section{Haematological parameter before treatment}

Table 2 summarises baseline haematological parameters before treatment in 127 study participants. Mean $( \pm S D)$ total white count before treatment was $224( \pm 139) \mathrm{K} / \mu \mathrm{L}$, Neutrophil 179 $( \pm 123) \mathrm{K} / \mu \mathrm{L}$ and basophil $3.3( \pm 4.5) \mathrm{K} / \mu \mathrm{L}$. Initial mean baseline eosinophil was significantly higher 
among males $7.68( \pm 15.8) \mathrm{K} / \mu \mathrm{L}$ than in females $3.34( \pm 4) \mathrm{K} / \mu \mathrm{L}(\mathrm{p}=0.002)$. The mean platelet counts were significantly higher in females $506( \pm 236.8) \mathrm{K} / \mu \mathrm{L}$ than in males $369.5( \pm 251) \mathrm{K} / \mu \mathrm{L}(\mathrm{p}=0.003)$.

Table 2: Haematological parameters of Ph positive CML patients before treatment

\begin{tabular}{lllll}
\hline Variable & $\begin{array}{l}\text { All } \\
\text { Mean(SD) }\end{array}$ & $\begin{array}{l}\text { Male } \\
\mathbf{n}(\%)\end{array}$ & $\begin{array}{l}\text { Female } \\
\mathbf{n}(\%)\end{array}$ & P value $^{*}$ \\
\hline Total wbc count $(\mathrm{K} / \mu \mathrm{l})$ & $224(139)$ & $210.9(117.3)$ & $246.6(169.5)$ & 0.207 \\
Absolute neutrophil count $(\mathrm{K} / \mu \mathrm{l})$ & $179(123)$ & $165(105)$ & $203(146.6)$ & 0.124 \\
Absolute basophil count $(\mathrm{K} / \mu \mathrm{l})$ & $3.3(4.5)$ & $2.9(2.7)$ & $3.9(6.4)$ & 0.211 \\
Absolute eosinophil count $(\mathrm{K} / \mu \mathrm{l})$ & $6.1(12.9)$ & $7.68(15.8)$ & $3.34(4)$ & 0.022 \\
$\begin{array}{l}\text { Platelets counts }(\mathrm{K} / \mu \mathrm{l}) \\
\text { Haemoglobin }(\mathrm{g} / \mathrm{dl})\end{array}$ & $420(254)$ & $369.5(251)$ & $506.1(236.8)$ & 0.003 \\
$\begin{array}{l}\text { Bone marrow blast }(\mathrm{n}=101) \\
\quad 0-5 \%\end{array}$ & $8.5(2.2) \mathrm{g} / \mathrm{dl}$ & $8.49(2.2) \mathrm{g} / \mathrm{dl}$ & $8.55(2) \mathrm{g} / \mathrm{dl}$ & 0.886 \\
$\quad$ & & & & 0.336 \\
$\quad$ EUTOS score & $18(65.4)$ & $56(67.5)$ & $27(32.5)$ & \\
Low risk $(\leq 87)$ & & $10(55.3)$ & $8(44.4)$ & \\
High risk $(>87)$ & $93(92)$ & $64(68.8)$ & $29(31.2)$ & $0.02 *$ \\
& $8(8)$ & $2(25 \%)$ & $6(75)$ &
\end{tabular}

Key: $\mathrm{wbc}=$ white blood cells; * Fisher's exact test; \#Test static was Pearson chi square, unless otherwise stated

\section{Duration of symptoms, time to diagnosis and time to treatment initiation}

Mean duration of symptoms was found to be $15( \pm 9)$ months ranging from o to 48 months with one patient having no symptoms and was diagnosed incidentally upon regular check-up and one patient with symptoms for 4 years. Mean duration from haematology consultation to final CML diagnosis was $3(0)$ weeks and mean duration from final CML diagnosis to treatment initiation was $3( \pm 0.9)$ weeks.

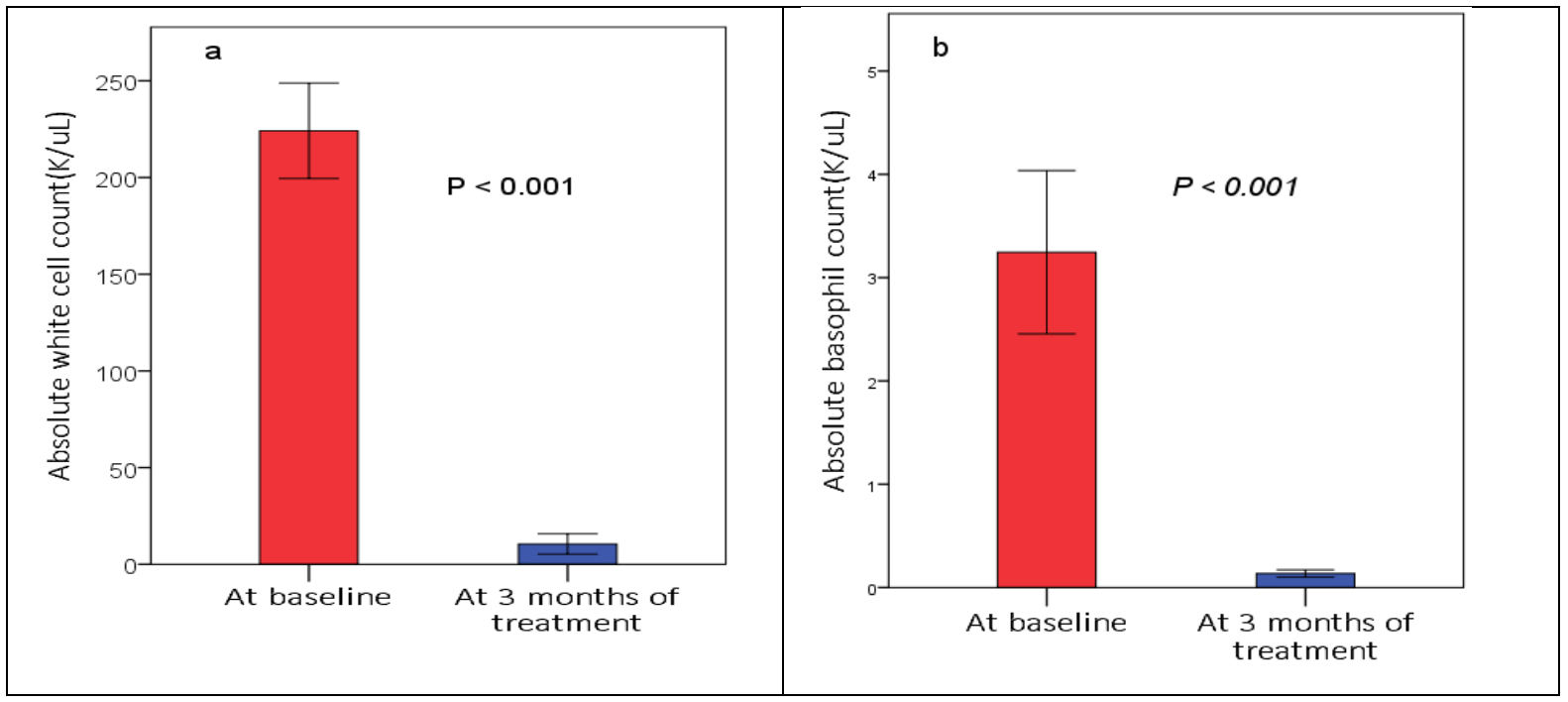




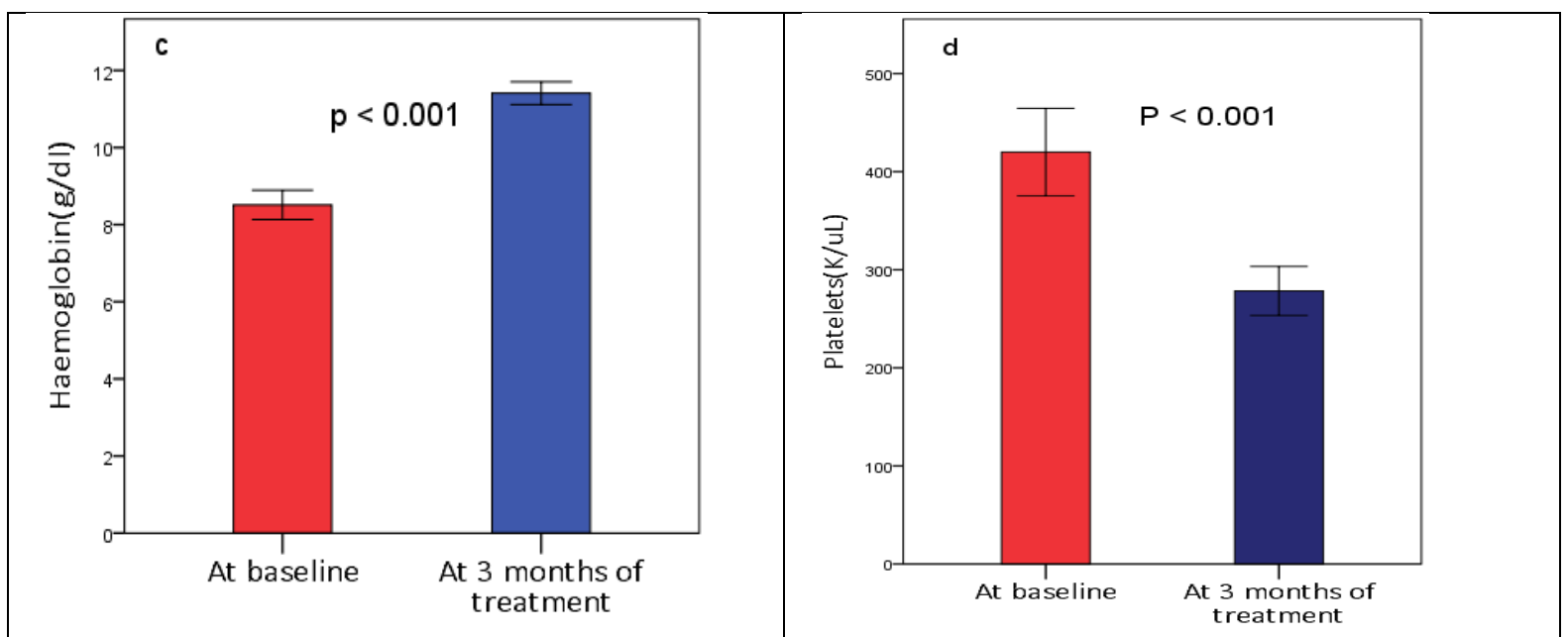

Figure 1: Baseline (before treatment) and after treatment mean of (a) white cell counts; (b) basophil; (c) haemoglobin; (d) platelets

\section{Haematological response to imatinib}

Of the 127 patients, 116 (91.3\%) had achieved complete haematological response to imatinib therapy within first three months while $11(8.7 \%)$ had not achieved complete haematological response. Out of 116 with complete haematological response $73(63 \%)$ were males and $43(37 \%)$ females. However, there was no association between complete haematological response and $\operatorname{sex}(p=1.00)$. Figure $1 a$, $1 \mathrm{~b}$ and $1 \mathrm{~d}$ respectively show the significant declines in white cell counts, basophils and platelets while Figure $1 c$ displays the significant increase in haemoglobin (all $p<0.001$ ).

\section{Discussion}

This study revealed that $\mathrm{Ph}$ positive $\mathrm{CML}$ patients receiving imatinib in Tanzania are relatively younger in age and mainly present with anaemia, leucocytosis and splenomegaly. Despite the duration of symptoms found being longer, the time to diagnosis and time to treatment initiation was reasonable and majority of patients achieved complete haematological remission in three months of treatment. In developed countries, CML Philadelphia chromosome positive is mainly a disease that affect people in their $4^{\text {th }}$ and $5^{\text {th }}$ decades of life (Stefan Faderl, 1999). This slightly contrasts with the findings of the current study, in which patients were a decade younger disclosing a population of patients who are in the socio-economic prime of their lives. The younger age at presentation remains a controversial issue, and is yet to be established whether this is a mere reflection of the country demographics or a true difference in population genetics or disease biology. These findings have consolidated the knowledge on CML demographic pattern in SubSaharan Africa (Mendizabal et al., 2013; Oyekunle et al., 2015).

In this study, there was a male predominance of 1.7:1 similar to reports by other workers (Berger et al., 2005; Björkholm et al., 2011). Since CML is not a sex linked disorder, it is highly unlikely that sex influences rates of genetic mutations, a sensible logic in this male predominance can be related to sex-specific differences in immune system regulation (Smith et al., 2011). The high rates of anaemia and splenomegaly with few constitutional symptoms in this study require special attention. This might explain the late presentations of study participants with disease progression, severe symptoms and extramedullary haematopoiesis. Our findings may also suggest that CML in African patients presents with a more severe phenotype form from the beginning as seen in many other malignancies including non-Hodgkin lymphoma and breast cancer (Newman et al., 2002; Xue et al., 2014). A study by Savage et al. (1997) reported relatively lower rates of anaemia (33.5\%) and abdominal distension was (14.8\%). The differences in these studies is due to the fact that the latter was conducted in the United Kingdom where there are superior healthcare standards with routine medical check-up, therefore malignancies including $C M L$ would be detected at an early stage. 
The apparent relative higher leukocyte counts in majority of our patients was a gauge and an additional indicator to the already observed clinical signs and symptoms of late presentations as $C M L$ is a progressive disease with inclining blood counts at each advancing stage. Similar counts have been reported among African patients in Kenya, Nigeria and Central Africa (Othieno-Abinya et al., 2002; Mukiibi et al., 2003; Oyekunle et al., 2015).

Mean duration of symptoms in this study might be considered long given the obvious symptoms of abdominal distension and fatigue to warrant immediate medical consultation and therefore referral to an appropriate referral hospital. A time period of more than three months has been used to indicate prolonged time to diagnosis for many cancers (Allgar \& Neal, 2005). A few studies have looked at time from symptoms onset to seeking physician consultations. For instance, Howell et al. (2013) found that duration of symptoms in CML was a little more than three months. The observed difference can be attributed to poor health seeking behaviour in our community, limited haematology specialists on top of the fact that CML initially presents as an indolent disease and patients do not realise that symptoms are serious enough. One other possibility is patient delays. In a study by Howell et al. (2015), CML patients did not think their symptoms were serious enough to seek medical attention.

Tropical conditions that lead to massive splenomegaly such as visceral leishmaniasis and chronic malaria infection could resemble CML clinically and since they are endemic in Tropical countries, this could delay impression of CML and subsequently late referral. Moreover, a complete blood count and good peripheral blood examination is not always possible in most primary health care facilities where patients initially report.

In this study, the mean time from final diagnosis to imatinib therapy initiation was three weeks. This was relatively lower compared to other studies elsewhere in Africa (Koffi et al., 2010; Oyekunle et al., 2015). The difference observed in this study is due to a strong referral system established between the diagnostic centre at Lancet laboratory, Muhimbili National Hospital and a special clinic specific for CML patients at ORCI. Three weeks from haematology consultation to final diagnosis is partly explained by the fact that fluorescent in situ hybridization test for Philadelphia chromosome is done at the private laboratory and takes a minimum of five working days from the time the sample has been collected.

There was an impressive rate of haematological response three months after treatment despite the late presentations and symptoms attributed to severe disease. This is explained by the potency and efficacy of the targeted therapy able to induce haematological remission later followed by both cytogenetic and molecular response. Many other similar studies have reported complete haematological response to range between $88 \%$ and 95\% (Jalaeikhoo et al., 2011; Nair et al., 2014; Sissolak et al., 2015). Although achieving complete haematological response within three months of therapy is associated with good overall survival and progression free survival (Hanfstein et al., 2015; Soverini et al., 2016), and a good marker of patient progress in alleviations of clinical symptoms, both cytogenetic and molecular remission remains good predictors of response to treatment. Therefore, regardless of severity of symptoms, late presentations and initial prognostic markers, more than $90 \%$ of $\mathrm{Ph}$ chromosome positive CML patients on imatinib therapy will achieve complete haematological remission in the first three months of therapy. For this reason, the effects of late presentations, severity of symptoms and prognostic scores can be better evaluated against cytogenetic and/or molecular remissions for these parameters to show association.

Strength of this study relies on the fact that these findings will help advocate for early CML diagnosis and strengthen early referral and reduce complications and early death in patients with CML. Although this was a cross-sectional study, participants were asked to recall time to diagnosis and time to treatment, of which in a few patients that this information could not be obtained from the files and therefore posing a challenge of recall bias.

In conclusion, majority of patients were young and presented late to hospital with clinical and laboratory findings of severe disease. The elucidated clinical and laboratory findings should advocate early CML diagnosis and immediate referral to a tertiary hospital. Haematological 
response was still achieved in majority of these patients with imatinib therapy suggesting that the management approach is effective.

\section{Acknowledgements}

We extend our gratitude to the patients who agreed to participate in the study. We also thank the $\mathrm{ORCl}$ administration for allowing us to do this study at the institution and staff at the CML clinic for their collaboration. The study received financial support from Catholic University of Health and Allied Sciences.

\section{References}

Allgar, V.L. \& Neal, R.D. (2005) Delays in the diagnosis of six cancers: analysis of data from the National Survey of NHS Patients: Cancer. British Journal Of Cancer 92, 1959-1970.

Baccarani. M., Cortes, J., Pane, F., Niederwieser, D., Saglio, G., Apperley, J., Cervantes, F., Deininger, M., Gratwohl, A., Guilhot, F., Hochhaus, A., Horowitz, M., Hughes, T., Kantarjian, H., Larson, R., Radich, J., Simonsson, B., Silver, R.T., Goldman, J., Hehlmann, R., European LeukemiaNet. (2009) Chronic myeloid leukemia: An update of concepts and management recommendations of European LeukemiaNet. Journal of Clinical Oncology 27,6041-6051.

Berger, U., Maywald, O., Pfirrmann, M., Lahaye, T., Hochhaus, A., Reiter, A., Hasford, J., Heimpel, H., Hossfeld, D.K., Kolb, H.J., Löffler, H., Pralle, H., Queisser, W., Hehlmann, R., German CMLStudy Group (2005) Gender aspects in chronic myeloid leukemia: long-term results from randomized studies. Leukemia 19, 984-989.

Magnus Björkholm, M., Ohm, L., Eloranta, S., Derolf, Å., Hultcrantz, M., Sjöberg, J., Andersson, T., Höglund, M., Richter, J., Landgren, O., Kristinsson, S.Y. \& Dickman, P.W. (2011). Success story of targeted therapy in chronic myeloid leukemia: a population-based study of patients diagnosed in Sweden from 1973 to 2008. Journal of Clinical Oncology 29, 2514-2520.

Busolo, D.S. \& Woodgate, R.L. (2015) Cancer prevention in Africa: a review of the literature. Global Health Promotion 22, 31-39.

Fialkow, P.J., Jacobson, R.J. \& Papayannopoulou, T. (1977) Chronic myelocytic leukemia: clonal origin in a stem cell common to the granulocyte, erythrocyte, platelet and monocyte/macrophage. American Journal of Medicine 63, 125-130.

Gupta, A. \& Prasad, K. (2007) Hematological and molecular response evaluation of CML patients on imatinib. Journal of the Association of Physicians of India 55, 109-113.

Hanfstein, B., Müller, M.C. \& Hochhaus, A. (2015) Response-related predictors of survival in CML. Annals of Hematology 94, 227-39.

Hasford, J., Baccarani, M., Hoffmann, V., Guilhot, J., Saussele, S., Rosti, G., Fuilhot, F., Porkka, K., Ossenkoppele, G.,Lindoerfer, D., Simonsson, B., Pfirrmann, M. \& Hehlmann, R. (2011) Predicting complete cytogenetic response and subsequent progression-free survival in 2060 patients with CML on imatinib treatment: the EUTOS score. Blood $118,686-692$.

Howell, D.A., Warburton, F., Ramirez, A.J., Roman, E., Smith, A.G. \& Forbes, L.J. (2015) Risk factors and time to symptomatic presentation in leukaemia, lymphoma and myeloma. British Journal of Cancer 113, 1114-1120.

Howell, D.A., Smith, A.G., Jack, A., Patmore, R., Macleod, U., Mironska, E. \& Roman, E. (2013) Timeto-diagnosis and symptoms of myeloma, lymphomas and leukaemias: a report from the Haematological Malignancy Research Network. BMC Hematology 13, 9.

Jalaeikhoo, H., Ahmadzadeh, A., Toogeh, G., Haybar, H., Valizadeh, A., Charoosaei, R., Yadollahzadeh, M. \& Keyhani, M. (2011) Six-year follow up of imatinib therapy for newly diagnosed chronic myeloid leukemia in Iranian patients. Archives of Iranian Medicine 14, 378380.

Koffi, K.G., Nanho, D.C., N'dathz, E., Kouehion, P., Dissieka, R., Attia, A., Mozard, K., Tolo, A., Boidy, 
K., Meité, N., Ayemou, R., Sekongo, M., Tea, N. \& Sanogo, I. (2010) The Effect of Imatinib Mesylate for Newly Diagnosed Philadelphia Chromosome-Positive, Chronic-Phase Myeloid Leukemia in Sub-Saharan African Patients: The Experience of Côte d'Ivoire. Advances in Hematology, 2010.

Mendizabal, A.M., Garcia-Gonzalez, P. \& Levine, P.H. (2013) Regional variations in age at diagnosis and overall survival among patients with chronic myeloid leukemia from low and middle income countries. Cancer Epidemiology, 37, 247-254.

Mukiibi, J.M., Nyirenda, C.M., Paul, B., Adewuyi, J.O., Mzula, E.L.B. \& Malata, H.N. (2013) Chronic myeloid leukaemia in Central Africans. East African Medical Journal, 80, 470-475.

Nair, V., Sharma, A., Kotwal, J., Bhikshapathy, M., Mishra, D.K., Das, S., Sharma, S., Kapoor, R., Singh, J., Nair, V., Uday, Y. \& Kotwal, A. (2014) Monitoring of response to therapy with imatinib mesylate in Chronic Myeloid Leukemia in chronic phase (CML-CP). Medical Journal, Armed Forces India 70, 315-320.

Neal, R.D. (2009) Do diagnostic delays in cancer matter? British Journal of Cancer 101, 9-12.

Newman, L.A., Bunner, S., Carolyn, K., Bouwman, D., Kosir, M.A., White, M. \& Schwartz, A. (2002) Ethnicity related differences in the survival of young breast carcinoma patients. Cancer 95, 2127.

Othieno-Abinya, N.A. et al., 2002. Chronic myeloid leukaemia at the Kenyatta National Hospital, Nairobi. East African Medical Journal 79, 593-597.

Oyekunle, A.A., Bolarinwa, R.A., Oyelese, A.T., Salawu, L. \& Durosinmi, M.A. (2015) Determinants of overall and progression-free survival of Nigerian patients with Philadelphia-positive chronic myeloid leukemia. Advances in Hematology 908708.

Rowley, J.D. (1973) A new consistent chromosomal abnormality in chronic myelogenous leukaemia identified by quinacrine fluorescence and Giemsa staining. Nature 243, 290-293.

Savage, D.G., Szydlo, R.M. \& Goldman, J.M. (1997) Clinical features at diagnosis in 430 patients with chronic myeloid leukaemia seen at a referral centre over a 16-year period. British Journal of Haematology 96, 111-116.

Siegel, R., Naishadham, D. \& Jemal, A., (2013) Cancer Statistics, 2013. CA: Cancer Journal for Clinicians $63,11-30$.

Sissolak, G., Badenhorst, J., Steenkamp, J., Heaney, M., Louw, V., Schnugh, D. \& Willem, P. (2015) Treatment outcomes in CML patients treated with tyrosine kinase inhibitors at a tertiary teaching hospital in South Africa. Clinical Lymphoma, Myeloma \& Leukemia 15, 803-810.

Smith, A., Howell, D., Patmore, R., Jack, A. \& Roman, E. (2011) Incidence of haematological malignancy by sub-type: a report from the Haematological Malignancy Research Network. British Journal of Cancer 105, 1684-1692.

Soverini, S., De Benedittis, C., Mancini, M. \& Martinelli, G. (2016) Best practices in chronic myeloid leukemia monitoring and management. The Oncologist 21, 626-633.

Stefan Faderl, M. (1999) The Biology of Chronic Myeloid Leukemia. New England Journal of Medicine 341, 164-172.

Weller, D., Vedsted, P., Rubin, G., Walter, F.M., Emery, J., Scott, S., Campbell, C., Andersen, R.S., Hamilton, W., Olesen, F., Rose, P., Nafees, S., van Rijswijk, E., Hiom, S., Muth, C., Beyer, M. \& Neal, R.D. (2012) The Aarhus statement: improving design and reporting of studies on early cancer diagnosis. British Journal of Cancer 106, 1262-7.

Xue, W.-Q., He, Yong-Qiao, H., Zhu, J-H., Ma, J-Q., He, J. \& Jia, W-H.(2014) Association of BRCA2 $\mathrm{N} 372 \mathrm{H}$ polymorphism with cancer susceptibility: a comprehensive review and meta-analysis. Scientific Reports 4, 6791. 